\title{
Temperature and timescale dependence of protein dynamics in methanol : water mixtures
}

\author{
Alexander L. Tournier, $\dagger^{a}$ Valerie Réat, ${ }^{b}$ Rachel Dunn, ${ }^{c}$ Roy Daniel, ${ }^{c}$ \\ Jeremy C. Smith ${ }^{a}$ and John Finney ${ }^{*} d$ \\ ${ }^{a}$ Computational Molecular Biophysics, Interdisciplinary Centre for Scientific Computing \\ (IWR), University of Heidelberg, Heidelberg, Germany \\ ${ }^{b}$ Institut de Pharmacologie et de Biologie Structurale, CNRS and UPS, Toulouse, France \\ ${ }^{c}$ Department of Biological Sciences, University of Waikato, Hamilton, New Zealand \\ ${ }^{d}$ Department of Physics and Astronomy, University College London, London, UK. \\ E-mail: j.finney@ucl.ac.uk
}

Received 11th November 2004, Accepted 21st February 2005

First published as an Advance Article on the web 2nd March 2005

Experimental and computer simulation studies have suggested the presence of a transition in the dynamics of hydrated proteins at around $180-220 \mathrm{~K}$. This transition is manifested by nonlinear behaviour in the temperature dependence of the average atomic mean-square displacement which increases at high temperature. Here, we present results of a dynamic neutron scattering analysis of the transition for a simple enzyme: xylanase in water : methanol solutions of varying methanol concentrations. In order to investigate motions on different timescales, two different instruments were used: one sensitive to $\sim 100$ ps timescale motions and the other to $\sim$ ns timescale motions. The results reveal distinctly different behaviour on the two timescales examined. On the shorter timescale the dynamics are dictated by the properties of the surrounding solvent: the temperature of the dynamical transition lowers with increasing methanol concentration closely following the melting behaviour of the corresponding water : methanol solution. This contrasts with the longer (ns) timescale results in which the dynamical transition appears at temperatures lower than the corresponding melting point of the cryosolvent. These results are suggested to arise from a collaborative effect between the protein surface and the solvent which lowers the effective melting temperature of the protein hydration layer. Taken together, the results suggest that the protein solvation shell may play a major role in the temperature dependence of protein solution dynamics.

\section{Introduction}

Experimental techniques such as Mössbauer spectroscopy, $\mathrm{X}$-ray diffraction and neutron scattering have suggested the presence of a transition in the internal dynamics of protein motions at $\sim 180-220 \mathrm{~K}^{1-9}$ This apparent dynamical transition has been observed to have similarities to the phase transition that appears in glass-forming liquids. ${ }^{10-13}$ The motions below the transition are believed to be mostly harmonic whereas the mean-square displacements above the transition are dominated by anharmonic contributions. Below the transition the protein may be trapped in local potential energy minima or 'conformational substates' of the protein. ${ }^{14}$ Above the transition, protein motion may involve diffusive-like motions involving jumps between substates.

The presence of conformational substates has been argued to be important for function. Myoglobin has been shown to have several conformational substates at low temperature with different functional properties. ${ }^{15,16}$ Also, function may depend on the ability of a protein to explore different substates in cases where the functional conformation is not the minimum-energy conformation but rather is induced through, for example, interaction with the ligand. However, for those enzymes that have been examined, the rate-limiting step for catalysis is unaffected by the ps-timescale $220 \mathrm{~K}$ dynamical transition. ${ }^{17,18}$ Moreover, dynamical transition temperatures have been shown to depend on the timescale investigated. ${ }^{19-21}$

$\dagger$ Present address: Biomolecular Modelling Laboratory, Cancer Research UK, Lincoln's Inn Fields, London, UK.
In order to further understand the relationship between protein dynamics and function, it is necessary to characterise the role of solvation. ${ }^{22}$ The presence of solvent affects the protein motion, effectively modifying the potential energy landscape the protein is exploring. Recent work argues for the presence of two types of processes: slaved and nonslaved. ${ }^{23}$ Nonslaved processes would correspond to processes which are independent of the solvent dynamics, whereas slaved processes would depend critically on solvent dynamics. Enzymatic activity such as bond formation would be a typical nonslaved process whereas opening and closing of channels would be a slaved process. A hydration-induced increase in flexibility is thought to be important for function. ${ }^{24}$ Neutron scattering experiments have shown protein dynamical amplitudes to increase upon hydration. ${ }^{25-27}$ One possibility is that, in the absence of water, protein sidechains form hydrogen bonds with each other thus rigidifying the protein. Upon hydration, some of these hydrogen bonds would be transferred to water molecules, with the effect that the sidechains diffuse more freely in the solvent. ${ }^{28-30}$

A number of experiments and simulations have indicated that when a protein is solvated the dynamical transition at $\sim 220 \mathrm{~K}$ is strongly coupled to the solvent. ${ }^{31,32}$ Neutron scattering experiments have shown that dry protein samples exhibit little motion at $300 \mathrm{~K}$ over that expected from a harmonic solid. ${ }^{33,34}$ The presence of highly-viscous solvents such as trehalose has been shown to abolish the dynamical transition. ${ }^{35}$

In the present work we investigate the dependence of the dynamical transition on solvent composition. In recent years a 
number of cosolvents have found a wide range of uses in biology: as cryosolvents, protein denaturants, protein fold stabilizers, protein function modulators, and more. ${ }^{30}$ In the present work methanol was used as cryosolvent. Methanol preserves protein structure and function at moderate concentrations although at higher concentration it tends to denature protein structure and promotes helix formation. ${ }^{30}$ Some cosolvents have been shown to interact with protein surfaces in very specific ways. ${ }^{28,30,36-38}$ Using neutron diffraction it was possible to locate specific cosolvent molecules on the protein surface. In studies on lysozyme, ethanol and dimethyl sulfoxide (DMSO) were found to interact mostly with the nonpolar ("hydrophobic") parts of the protein. ${ }^{36,37}$

In order to investigate the dynamics of methanol-based cryosolvent/protein solutions, neutron scattering techniques were employed here. Neutron scattering is able to probe directly the dynamics of proteins in solution. The present measurements were performed on the enzyme xylanase in solutions of different cryosolvent concentrations. Two different sets of experiments were performed at the Institut LaueLangevin (ILL) in Grenoble, on instruments corresponding to two different timescales: the IN6 instrument is sensitive to motions on the 100 ps timescale whereas the IN16 instrument is sensitive to nanosecond-timescale dynamics. The results indicate that on short timescales the protein dynamics closely follow the properties of the cryosolvent in which it is dissolved. In contrast, nanosecond-timescale motions appear to be relatively independent of the cryosolvent concentration above $\sim 15 \% \quad v / v$ methanol. This suggests that the protein surface may be preferentially solvated by methanol, lowering the effective melting point of the solvation shell surrounding the protein.

\section{Methods}

\section{Data collection}

The experiments were performed on a thermophilic xylanase enzyme in $\mathrm{D}_{2} \mathrm{O}$ and in $\mathrm{D}_{2} \mathrm{O}$-methanol mixtures. Xylanase was chosen as it is a relatively simple enzyme that is stable and active under all the experimental conditions of this study. ${ }^{39}$ The activity of xylanase is maintained under all the solvent conditions used here. ${ }^{18}$ The experiments were performed using hydrogen/deuterium exchanged proteins (twice dissolved in $\mathrm{D}_{2} \mathrm{O}$ and freeze-dried).

A first set of measurements was performed on the IN6 timeof-flight spectrometer at the Institut-Laue-Langevin in Grenoble. The methanol : water ratio was varied, ranging in concentration from $0 \% \mathrm{CD}_{3} \mathrm{OD} / 100 \% \mathrm{D}_{2} \mathrm{O}$ to $40 \% \mathrm{CD}_{3} \mathrm{OD} / 60 \%$ $\mathrm{D}_{2} \mathrm{O}$ (concentration in $v / v$ ). Deuterated solvents were used to reduce the scattering contribution from the solvent. The incident wavelength used was $5.12 \AA$. The energy resolution of the apparatus was $50 \mu \mathrm{eV}$, such that motions on the timescale of $\sim 100$ ps and below are accessed. All data were collected with the sample holder oriented at $135^{\circ}$ relative to the incident beam. The samples were contained in aluminium flat-plate cells of $0.5 \mathrm{~mm}$ thickness. Neutron scattering intensities were recorded on the following samples: $63 \mathrm{mg}$ xylanase in $100 \%$ $\mathrm{D}_{2} \mathrm{O}, 70 \mathrm{mg}$ xylanase in $3.5 \% \quad v / v \quad \mathrm{CD}_{3} \mathrm{OD} / \mathrm{D}_{2} \mathrm{O}, 72 \mathrm{mg}$ xylanase in $7 \% v / v \mathrm{CD}_{3} \mathrm{OD} / \mathrm{D}_{2} \mathrm{O}, 68 \mathrm{mg}$ xylanase in $15 \% v / v$ $\mathrm{CD}_{3} \mathrm{OD} / \mathrm{D}_{2} \mathrm{O}, 71 \mathrm{mg}$ xylanase in $20 \% v / v \mathrm{CD}_{3} \mathrm{OD} / \mathrm{D}_{2} \mathrm{O}, 76 \mathrm{mg}$ xylanase in $25 \% v / v \mathrm{CD}_{3} \mathrm{OD} / \mathrm{D}_{2} \mathrm{O}$ and $66 \mathrm{mg}$ xylanase in $40 \%$ $v / v \mathrm{CD}_{3} \mathrm{OD} / \mathrm{D}_{2} \mathrm{O}$. The measured transmissions of these samples (and their corresponding concentration) were $0.92(63 \mathrm{mg}$ $\left.\mathrm{ml}^{-1}\right), 0.91\left(70 \mathrm{mg} \mathrm{ml}^{-1}\right), 0.88\left(72 \mathrm{mg} \mathrm{ml}^{-1}\right), 0.91\left(68 \mathrm{mg} \mathrm{ml}^{-1}\right)$, $0.89\left(68 \mathrm{mg} \mathrm{ml}^{-1}\right), 0.92\left(72 \mathrm{mg} \mathrm{m}^{-1}\right)$ and $0.90\left(63 \mathrm{mg} \mathrm{ml}^{-1}\right)$, respectively.

Data were collected over the temperature range from $100 \mathrm{~K}$ to $300 \mathrm{~K}$ for each methanol concentration. The samples were first cooled to $\sim 100 \mathrm{~K}$ and then slowly reheated in steps back to $300 \mathrm{~K}$ over a period of $\sim 6 \mathrm{~h}$, during which time the data were recorded. The measured elastic intensity was normalized to $115 \mathrm{~K}$ to remove coherent scattering contributions.

Data were also collected on IN16, a back-scattering spectrometer with a higher energy resolution of $1.2 \mu \mathrm{eV}$ that is capable of resolving motions on approximately the nanosecond timescale and below. These measurements were again performed on the enzyme xylanase at different $\mathrm{CD}_{3} \mathrm{OD} / \mathrm{D}_{2} \mathrm{O}$ concentrations. Five samples were run on IN16: $81 \mathrm{mg}$ xylanase in $\mathrm{D}_{2} \mathrm{O}, 95 \mathrm{mg}$ xylanase in $15 \% v / v \mathrm{CD}_{3} \mathrm{OD} / \mathrm{D}_{2} \mathrm{O}, 75 \mathrm{mg}$ xylanase in $27 \% v / v$ $\mathrm{CD}_{3} \mathrm{OD} / \mathrm{D}_{2} \mathrm{O}, 75 \mathrm{mg}$ xylanase in $40 \% v / v \mathrm{CD}_{3} \mathrm{OD} / \mathrm{D}_{2} \mathrm{O}$ and $69 \mathrm{mg}$ xylanase in $70 \% v / v \quad \mathrm{CD}_{3} \mathrm{OD} / \mathrm{D}_{2} \mathrm{O}$. The data were collected with sample holder oriented at $135^{\circ}$ relative to the incident beam. The samples were contained in aluminium flatplate cells of $0.5 \mathrm{~mm}$ path length. The measured transmissions (and respective protein concentrations) were $0.92\left(76 \mathrm{mg} \mathrm{m}^{-1}\right.$ ), $0.92\left(88 \mathrm{mg} \mathrm{ml}^{-1}\right), 0.95\left(71 \mathrm{mg} \mathrm{ml}^{-1}\right), 0.94\left(71 \mathrm{mg} \mathrm{ml}^{-1}\right)$ and $0.97\left(66 \mathrm{mg} \mathrm{ml}^{-1}\right)$, respectively. Samples were cooled to $80 \mathrm{~K}$ then heated progressively to $320 \mathrm{~K}$ over $22 \mathrm{~h}$, during which time the data were collected. The measured elastic intensity was normalized to $80 \mathrm{~K}$ to remove coherent scattering contributions.

\section{Data analysis}

Thermal neutrons are especially sensitive to slow, thermal motions. ${ }^{40,41}$ Neutrons scatter strongly from hydrogen nuclei for which they have a 10 times larger incoherent scattering cross section than for any other nucleus. Using selective deuteration-i.e. deuterated solvent plus exchanged hydrogens on the protein - in principle allows us to focus on the dynamics of the interesting parts of the system, in the present case, the protein.

In the Gaussian approximation the incoherent scattering function, $S_{\text {inc }}$, can be expressed as:

$$
S_{\text {inc }}(q, \omega=0)=\frac{1}{N} \sum_{i} b_{i}^{2} \exp \left(-\frac{q^{2}}{6}\left\langle u_{i}^{2}\right\rangle\right)
$$

where $q$ is the scattering vector, $\hbar \omega$ the energy transfer, $N$ the number of atoms, $b_{i}$ the scattering length and $\left\langle u_{i}^{2}\right\rangle$ the mean square displacement of atom $i$.

Assuming all atoms to be identical, the sum of Gaussians in eqn. (1) can be approximated by a single Gaussian, thus allowing the average mean-square-displacement, $\left\langle u^{2}\right\rangle$, of the atoms in the system to be obtained from the slope of the plot of $\ln S_{\text {inc }}(q, \omega=0) v s . q^{2}$. However, the procedure for obtaining mean-square displacements in this way is subject to a number of approximations that have been demonstrated to underestimate $\left\langle u^{2}\right\rangle$ by as much as $30 \%$ depending on the instrument used. $^{42}$

An alternative way of obtaining the mean-square fluctuation of the protein, $\left\langle u^{2}\right\rangle$ is directly from the integrated peak intensity $S_{\mathrm{INT}}=\sum S_{\mathrm{inc}}\left(q_{i}, \omega=0\right)$. This approach has the advantage that it does not rely on fitting the low $q$ region of the scattering data, a procedure that is often made difficult by statistical noise. This simpler approach uses the statistically stronger integrated peak intensities to calculate the $\left\langle u^{2}\right\rangle$. $S_{\text {INT }}$ is expressed as:

$$
S_{\mathrm{INT}}=C-\sum_{i} b^{2} \frac{q_{i}^{2}}{6}\left\langle u^{2}\right\rangle
$$

where $C$ is a constant. This procedure was used to determine the $\left\langle u^{2}\right\rangle$ in the present study. The integrated elastic peak intensities, $S_{\mathrm{INT}}(T)$, were determined by summing $S_{\mathrm{INT}}(q, \omega=$ $0, T)$ from $q=0.35 \AA^{-1}$ to $q=1.05 \AA^{-1}$. This range of $q$ was chosen to lie in the Gaussian scattering region. $S_{\text {INT }}(T)$ provides a qualitative guide of dynamic transition behaviour, with good counting statistical accuracy. ${ }^{34} S_{\text {INT }}$ was normalised to $T_{0}=115 \mathrm{~K}$ for IN16 and to $T_{0}=80 \mathrm{~K}$ for IN6 such that 
Table 1 Average protein and solvent contributions to the total scattering cross sections for the different samples used (in $\mathrm{mm}^{2} \mathrm{ml}^{-1}$ )

\begin{tabular}{llrr}
\hline & \multicolumn{1}{l}{$\sigma_{\text {inc }}$} & \multicolumn{1}{c}{$\sigma_{\text {coh }}$} & $\sigma_{\text {inc }}+\sigma_{\text {coh }}$ \\
\hline Protein & $27.9( \pm 2.8)$ & $2.1( \pm 0.2)$ & $30.0( \pm 3.0)$ \\
Solvent & $12.3( \pm 0.5)$ & $46.8( \pm 1.6)$ & $59.5( \pm 2.2)$ \\
Total & $40.2( \pm 2.8)$ & $48.9( \pm 1.6)$ & $89.5( \pm 3.7)$ \\
\hline
\end{tabular}

$\left\langle u^{2}\right\rangle_{\mathrm{T}}^{\text {normalised }}=\left\langle u^{2}\right\rangle_{T}-\left\langle u^{2}\right\rangle_{T_{0}}$. In comparing the results from IN6 and IN16 the difference in the baseline temperature used for normalisation leads to a relative increase in the $\left\langle u^{2}\right\rangle$ values calculated for IN6 estimated to be $\sim 0.05 \AA^{2}$.

\section{Solvent scattering}

Using knowledge of the isotopic scattering cross sections and the isotopic compositions of the various samples allowed the protein and solvent contributions to the scattering intensity to be estimated. The results presented in Table 1 indicate that, for the protein solutions, about $50 \%$ of the scattering is incoherent and $50 \%$ coherent. $70 \%$ of the incoherent scattering originates from the protein, due to the strong hydrogen contribution. $30 \%$ of the incoherent scattering originates from the solvent atoms and influences the observed scattering profile in a manner dependent on the solvent dynamics and the region of $q, \omega$ space examined. Most of the coherent scattering originates from the solvent. The self-coherent contribution to this, which is strongest in the low $q$ regime considered here (below $\sim 1 \AA^{-1}$ ), is dynamic in origin. In addition, there is a contribution originating from cross-correlations. The intramolecular 'Bragg' part of this contribution lies at $q$ values higher than those used here. However, a structural 'small-angle' scattering contribution can also exist in the same $q$-range as the selfcoherent and incoherent scattering. The small-angle scattering can be distinguished from the dynamic self-coherent scattering by its $q$-dependence. To remove the temperature-independent small-angle scattering, in the present work the scattering profiles were normalized with respect to the intensities at low temperatures $(115 \mathrm{~K}$ and $80 \mathrm{~K}$, respectively, on IN6 and IN16). However, the remaining background scattering due to the solvent has been shown to contribute significantly to the displacements calculated from neutron scattering data. ${ }^{43}$ The results in Hayward et al. ${ }^{43}$ indicate that the solvent is expected to contribute a constant background to the elastic peak intensity until the solution reaches its melting temperature. At this point the contribution from the solvent diminishes sharply as the motions of the solvent move out of the time windows of the instrument. This produces a saturation feature in the integrated peak intensities in IN6 and IN16 above $\sim 280 \mathrm{~K}$. The protein contribution to the measured $\left\langle u^{2}\right\rangle$ adds to the solvent contribution as a steady increase with temperature of the $\left\langle u^{2}\right\rangle$ above the dynamical transition temperature. ${ }^{43}$ In the present experiments it is difficult to dissociate the contributions coming from the protein from those coming from the solvent as the maximum slope in the transition is seen to coincide with the solvent melting point.

The general lowering of the transition temperature with increasing methanol concentration that is observed in these results (see below) could be due to the contribution of the solvent. Methanol is a bigger molecule than water and is less mobile. Scattering from methanol contributes $65 \%$ of the total solvent background scattering at $70 \%$ methanol concentration. This slow component to scattering would make a contribution to the elastic peak intensity that would not vanish at high temperatures, artificially lowering the average $\left\langle u^{2}\right\rangle$ at high temperatures.

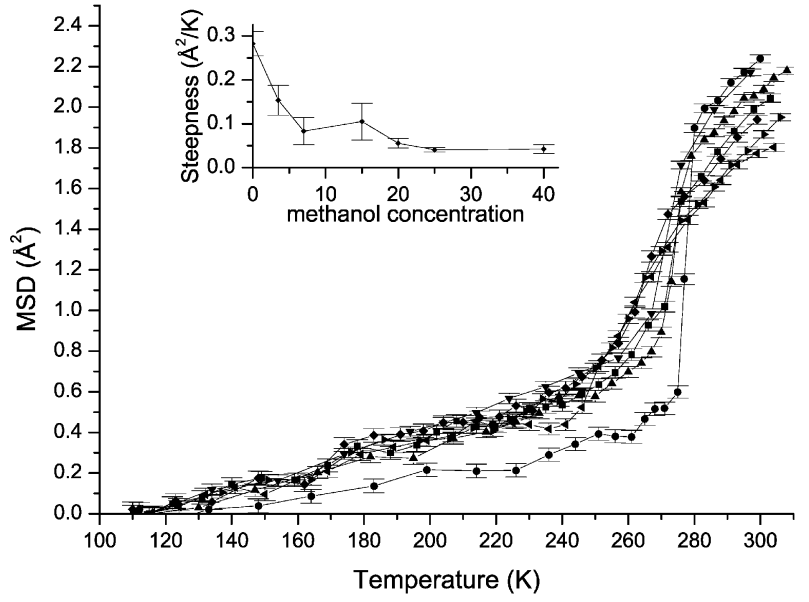

Fig. 1 IN6 Mean-square displacement vs. temperature for the protein in pure $\mathrm{D}_{2} \mathrm{O}(-\mathbf{-}-), 3.5 \% \quad v / v \quad \mathrm{CD}_{3} \mathrm{OD} / \mathrm{D}_{2} \mathrm{O} \quad(-\boldsymbol{\Delta}-), 7 \% \quad v / v$ $\mathrm{CD}_{3} \mathrm{OD} / \mathrm{D}_{2} \mathrm{O} \quad(-\boldsymbol{\nabla}-), \quad 15 \% \quad v / v \quad \mathrm{CD}_{3} \mathrm{OD} / \mathrm{D}_{2} \mathrm{O} \quad(-\mathbf{-}-), \quad 20 \%$ $v / v \mathrm{CD}_{3} \mathrm{OD} / \mathrm{D}_{2} \mathrm{O}(\longrightarrow), 25 \% v / v \mathrm{CD}_{3} \mathrm{OD} / \mathrm{D}_{2} \mathrm{O}(\longrightarrow-)$, and $40 \%$ $v / v \mathrm{CD}_{3} \mathrm{OD} / \mathrm{D}_{2} \mathrm{O}(-<)$. The maximum slope of the $\left\langle u^{2}\right\rangle$ data for the different methanol concentrations is presented as an inset.

\section{Results}

\section{Mean-square-displacements}

$\left\langle u^{2}\right\rangle$ obtained for the different samples on the fast timescale instrument, IN6, are presented in Fig. 1. The $\left\langle u^{2}\right\rangle$ for the protein in pure $\mathrm{D}_{2} \mathrm{O}$ increases slowly with temperature up to $275 \mathrm{~K}$, with no marked transition but a gradual increase in slope from $250-275 \mathrm{~K}$. There is a sharp transition between $275 \mathrm{~K}$ and $280 \mathrm{~K}$, occurring across the solvent melting point ( $277 \mathrm{~K}$ for $\left.\mathrm{D}_{2} \mathrm{O}\right)$. This strongly nonlinear increase of $\left\langle u^{2}\right\rangle$ with temperature is consistent with the activation of anharmonic dynamics on the sub $\sim 100$ ps timescale of the experiment.

The general form of $\left\langle u^{2}\right\rangle$ for xylanase in the different methanol/water solutions is similar to that of xylanase in pure $\mathrm{D}_{2} \mathrm{O}$. However, several differences are apparent. The increase in $\left\langle u^{2}\right\rangle$ with temperature from $120 \mathrm{~K}$ to $\sim 240 \mathrm{~K}$ is greater in the mixed solvent systems than in pure $\mathrm{D}_{2} \mathrm{O}$, indicating that the presence of methanol - even in small concentrations - leads to larger displacements at low temperatures than does pure $\mathrm{D}_{2} \mathrm{O}$. Furthermore, the onset of the transition moves to lower temperatures with increasing methanol concentrations (see Table 2). Whereas a sharp transition around $275 \mathrm{~K}$ is visible in the $3.5 \% \mathrm{CD}_{3} \mathrm{OD} / 96.5 \% \mathrm{D}_{2} \mathrm{O}$ data set, the transition is smoother at higher concentrations. The 'sharpness' of this dynamical transition can be estimated from the maximum

Table 2 Onset and midpoint temperatures of the transition at the different methanol concentrations measured on IN6 and IN16

\begin{tabular}{llll}
\hline & $\begin{array}{l}\text { Methanol } \\
\text { concentration } \\
\left(\% \mathrm{CD}_{3} \mathrm{OD} / \mathrm{D}_{2} \mathrm{O} v / v\right)\end{array}$ & $\begin{array}{l}\text { Onset of } \\
\text { transition/K }\end{array}$ & $\begin{array}{l}\text { Midpoint of } \\
\text { transition/K }\end{array}$ \\
\hline IN6 & 0 & $275( \pm 2)$ & $276( \pm 2)$ \\
& 3.5 & $267( \pm 2)$ & $274( \pm 3)$ \\
& 7 & $265( \pm 3)$ & $271( \pm 4)$ \\
& 15 & $267( \pm 3)$ & $273( \pm 2)$ \\
& 20 & $255( \pm 5)$ & $264( \pm 4)$ \\
& 25 & $253( \pm 5)$ & $262( \pm 4)$ \\
& 40 & $240( \pm 3)$ & $250( \pm 6)$ \\
& & & $277( \pm 2)$ \\
& 0 & $270( \pm 2)$ & $268( \pm 2)$ \\
& 15 & $200( \pm 10)$ & $255( \pm 4)$ \\
& 10 & $170( \pm 5)$ & $241( \pm 5)$ \\
& 10 & $170( \pm 5)$ & $210( \pm 10)$ \\
\hline
\end{tabular}




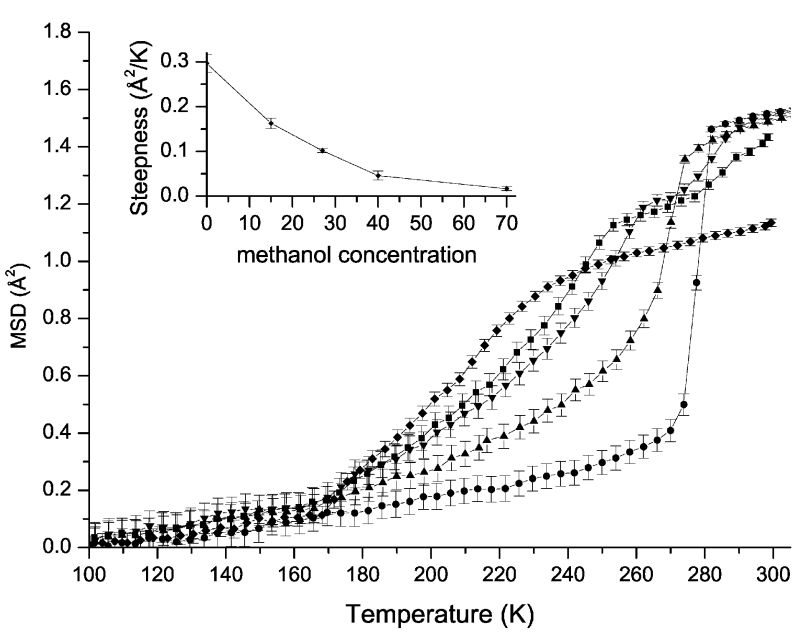

Fig. 2 IN16 Mean-square displacement vs. temperature for the protein in pure $\mathrm{D}_{2} \mathrm{O}(--), 15 \% v / v \mathrm{CD}_{3} \mathrm{OD} / \mathrm{D}_{2} \mathrm{O}(-\boldsymbol{\Delta}-), 27 \% v / v$ $\mathrm{CD}_{3} \mathrm{OD} / \mathrm{D}_{2} \mathrm{O}(-\boldsymbol{\nabla}-), 40 \% v / v \mathrm{CD}_{3} \mathrm{OD} / \mathrm{D}_{2} \mathrm{O}(-\mathbf{-}-)$, and $70 \% v / v$ $\mathrm{CD}_{3} \mathrm{OD} / \mathrm{D}_{2} \mathrm{O}(--)$. The maximum slope of the $\left\langle u^{2}\right\rangle$ data for the different methanol concentrations is presented as an inset.

gradient, at the midpoint of the transition. The concentration dependence of this gradient is shown in the inset of Fig. 1, which quantifies the effect of the transition becoming much less sharp for concentrations above $\sim 10 \% \mathrm{CD}_{3} \mathrm{OD}$. Fig. 1 also shows that $\left\langle u^{2}\right\rangle$ at temperatures above the transition decreases with increasing concentrations of methanol. This is consistent with an increase in solvent viscosity due to the presence of methanol. $^{44}$

The corresponding data obtained from IN16 are shown in Fig. 2. As for IN6, the $0 \%$ methanol data exhibit a slow increase in $\left\langle u^{2}\right\rangle$ at low temperatures until a marked transition appears, again at $277 \mathrm{~K}$, coinciding with the melting temperature of the $\mathrm{D}_{2} \mathrm{O}$ solution. At higher methanol concentrations the onset of the transition i.e. the point above which $\left\langle u^{2}\right\rangle$ starts increasing with temperature more rapidly, is $\sim 170 \mathrm{~K}$. Thus, there is a relatively sharp change in dynamical behaviour from the linear regime below $170 \mathrm{~K}$ to a steeper, initially linear, increase in $\left\langle u^{2}\right\rangle$ above $170 \mathrm{~K}$. The steepness of the transition is also presented in the inset in Fig. 2, showing the transition again to become less sharp with increasing methanol concentration.

The $\left\langle u^{2}\right\rangle$ data exhibits a plateau at high temperatures. This feature is more pronounced for the nano-second timescale. The temperature of onset of the plateau decreases with increasing methanol concentration, going from $277 \mathrm{~K}$ at $0 \%$ methanol down to $240 \mathrm{~K}$ for $70 \%$ methanol on IN16. Moreover the amplitude of the dynamics at high temperatures is seen to generally diminish with increasing methanol concentration, though the differences for the three lower concentrations are small.

Table 2 lists the temperatures of onset of the transition and temperatures of its midpoint at the different methanol concentrations as measured on IN6 and IN16.

\section{Discussion}

The sharp transition at $277 \mathrm{~K}$ seen in both the IN6 and IN16 data for $0 \%$ methanol coincides with the freezing point of $\mathrm{D}_{2} \mathrm{O}$. This suggests that pure $\mathrm{D}_{2} \mathrm{O}$ dominates the motions in the solution. Below $277 \mathrm{~K}$, the protein, which together with its solvent, had been previously cooled to very low temperatures of $115 \mathrm{~K}$ or below, is caged in ice and cannot move freely; hence the very low $\left\langle u^{2}\right\rangle$.

Another feature common to the IN6 and IN16 data is that $\left\langle u^{2}\right\rangle$ at high temperatures $(>280 \mathrm{~K})$ decreases with increasing methanol concentration (Figs. 1 and 2). This may arise from reduced diffusion due to the increase in viscosity of the solution

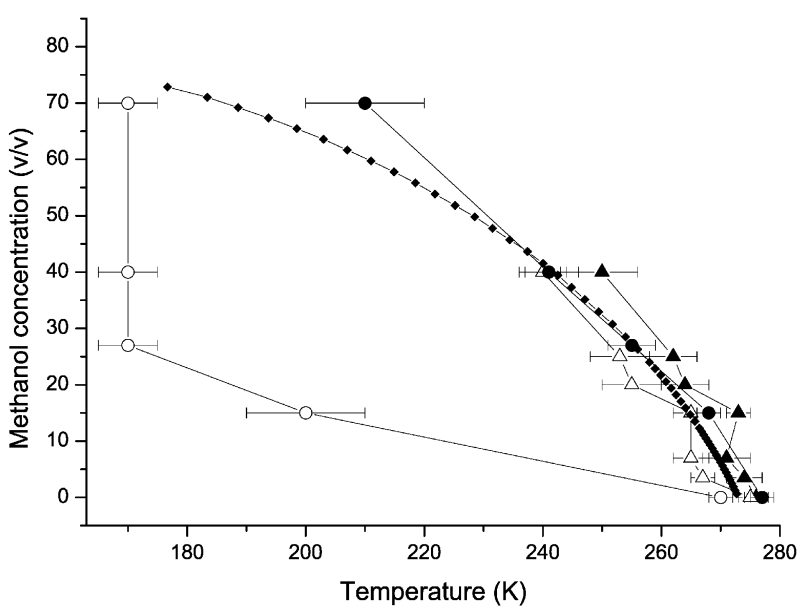

Fig. 3 Methanol/water mixture freezing point as a function of methanol/water concentration $(v / v)(--)$. For comparison the plot presents the temperature of the onset of the transition $(-\Delta-,-\mathrm{O}-)$, and the temperature of steepest slope of the MSD plots ( $\left.-\boldsymbol{\Lambda}-,-\mathbf{O}_{-}\right)$, for both the IN6 and IN16 data (respectively).

with increasing methanol concentration. ${ }^{44}$ This explanation is consistent with the IN6 data, for which the high temperature $\left\langle u^{2}\right\rangle$ decreases with increasing methanol concentration up to $40 \%$, the highest concentration measured on this instrument. However this hypothesis would not explain why the decrease in $\left\langle u^{2}\right\rangle$ continues in the IN16 data (Fig. 2) for methanol concentrations higher than $40 \%$, as at about this concentration the viscosity of bulk methanol : water solutions actually starts to decrease with increasing methanol concentration. ${ }^{44}$

The dynamical transition onset temperature under discussion is generally lowered in the IN16 data by $\sim 70 \mathrm{~K}$; in only pure $\mathrm{D}_{2} \mathrm{O}$ is the transition maintained at around the melting point of pure $\mathrm{D}_{2} \mathrm{O}\left(\sim 4{ }^{\circ} \mathrm{C}\right)$ on both instruments. An explanation for this effect may be found in the different timescales of the dynamics observed with the different instruments: ${ }^{19-21,45}$ IN6 is sensitive to motions on the sub $\sim 100$ ps timescale whereas IN16 can observe motion on the ns timescale. Therefore, motions appearing at a given temperature on the ns timescale of IN16 would appear only at higher temperatures in the $\sim 100$ ps timescale of IN6. The high-temperature plateaux in the IN16 $\left\langle u^{2}\right\rangle$ data arise due to the energy resolution function, as explained in Becker and $\mathrm{Smith}^{45}$ and Becker et al. $^{21}$

\section{Comparison with properties of methanol/water mixtures}

Fig. 3 presents the methanol/water freezing point as a function of temperature and methanol/water concentration (taken from refs. 44 and 46). We note that these data are for the behaviour of hydrogenated solvents; for the deuterated solvents we are comparing with, we would expect all the temperatures to be higher but by no more than a few degrees (for example, pure $\mathrm{D}_{2} \mathrm{O}$ melts at a temperature $4{ }^{\circ} \mathrm{C}$ higher than $\mathrm{H}_{2} \mathrm{O}$, while the melting point difference between hydrogenated and deuterated methanol is even less). For comparison the temperatures of maximum slope of $\left\langle u^{2}\right\rangle$, i.e., the midpoint of the transition (see Table 2), are presented on the same plot. As shown by previous work, ${ }^{43}$ the midpoint of transition - the temperature of maximum slope - can be identified with the melting temperature of the solvent. For both the IN6 and IN16 experiments the transition midpoint is seen to follow the methanol/water freezing point closely, certainly within the estimated error of the temperatures determined from the observed transitions. Due to the difference in the timescale under investigation, the IN6 midpoint is shifted to higher temperature compared to the IN16 results - a result also consistent with the conclusions of Hayward et al. ${ }^{43}$ 
Fig. 3 also presents the temperatures corresponding to the onset of the dynamical transition for the different methanol concentrations on the two instruments. A qualitatively different picture emerges here. Whereas the IN6 onset temperatures again follow the methanol/water freezing point curve, the IN16 results do not, and depart dramatically from both the melting line and the IN6 onset temperatures. On IN16 the onset of the dynamical transition appears at temperatures much lower than the melting point of the solution.

Although a conclusive explanation for the above behaviour is difficult to deduce, a possibility can be suggested. The data can be rationalised if the hypothesis is considered, that the protein is preferentially solvated by methanol. Cosolvents have been shown to solvate proteins by displacing some of the looser water molecules on a protein surface. ${ }^{28,30,36}$ In this case, then, we could expect that in the methanol/water mixtures the protein disturbs the solvent around it in such a way that it effectively freezes - or melts - at much lower temperatures than the bulk. In this context, we recall that crystallographic measurements discussed earlier ${ }^{28,30,36-38}$ conclude that, for example, ethanol interacts with the protein surface through contact with nonpolar groups on the surface. Therefore, we might well expect preferential association of methanol molecules with nonpolar parts of the protein surface. Further, recent structural studies of the methanol-water solutions themselves show microsegregation behaviour of the alcohol component even at relatively low concentrations (see for example refs. 47-49). These microscopically-associating methanol molecules interact through their respective nonpolar methyl groups. Therefore, it is these clusters, rather than single methanol molecules, that are likely to interact with nonpolar parts of the protein surface, enhancing further any preferential solvation effects.

This points towards the existence of a collaborative effect between the protein and methanol which results in a hydration shell around the protein that contains excess methanol, interacting with the surface through the nonpolar groups on the surface in a way consistent with results from related crystallographic and solution scattering measurements. The hydration shell would then exhibit a melting temperature much reduced relative to that of the nominal concentration of the bulk solvent. The lowest temperature at which we would expect to see a freeing up of motions due to the melting of this shell would be the lowest temperature at which liquid is found to exist in the methanol-water system. For the hydrogenous methanol-water system, this lowest temperature is at $156 \mathrm{~K} .{ }^{50}$ Considering that the corresponding minimum temperature for the deuterated system is likely to be several degrees higher than this, the observed lowest transition temperature of $170 \pm 5 \mathrm{~K}$ on IN16 (Table 2) would seem to be consistent with this hypothesis.

The question remains as to why the IN6 experiment does not show the presence of this preferential solvation layer. A possible explanation can again be proposed by considering the results of Hayward et al., ${ }^{43}$ which decomposed the changes in the neutron scattering intensity of the total system solvent + protein into the contributions from the solvent and protein separately. On longer timescales, the onset of changes in the dynamics of the protein occurs at significantly lower temperatures than on the shorter timescales. These results suggest that the onset of the transition we see on IN16 comes from the longer timescale protein motions being loosened up by the methanol rich solvent shell. On the shorter (IN6) timescale, the protein motions start at a temperature higher than the melting point of the solvent, and are therefore masked by the solvent contribution to the transition.

\section{Conclusion}

The results discussed above suggest that in pure water, the solvent dictates the motions of the protein solution. Increased dynamics is activated only at $277 \mathrm{~K}$, a temperature corresponding to the solvent melting temperature. On both timescales examined, the presence of methanol at concentrations as low as $3.5 \%$ considerably loosens protein dynamics compared to pure water solvent. The temperature at the onset of the transition in the mean-square displacement is seen to decrease with increasing methanol concentrations: going from $270 \mathrm{~K}$ for pure water down to $240 \mathrm{~K}$ for $40 \%$ methanol on IN6 and down to $170 \mathrm{~K}$ for $30 \%$ methanol and above on IN16.

Comparison of the protein dynamics at different methanol concentrations with the bulk properties of methanol/water mixtures suggests a collaborative effect between the protein surface and methanol molecules involving a methanol-rich solvation shell around the protein. This solvation-shell melts at temperatures that are much lower than the melting temperature of the cryosolvent of the nominal concentration. On the longer timescales, it is this temperature that is measured as the dynamic transition temperature, underlining the strong influence of the solvation shell on the ns dynamics of the protein. On shorter timescales $(\sim 100 \mathrm{ps})$, the bulk properties of the cryosolvent dictate the dynamics of the system and set the observed dynamical transition temperature.

\section{Acknowledgements}

We thank the Institut Laue-Langevin for provision of neutron beam time, and the local contacts Bernhard Frick and Jacques Ollivier for experimental assistance.

\section{References}

1 F. Parak and H. Formanek, Acta Crystallogr., Sect. A: Fundam. Crystallogr., 1971, A27, 573-578.

2 H. Frauenfelder, G. A. Petsko and D. Tsernoglou, Nature, 1979, 280, 558-563.

3 F. Parak, E. N. Frolov, R. L. Mossbauer and V. I. Goldanskii, J. Mol. Biol., 1981, 145, 825-833.

4 S. G. Cohen, E. R. Bauminger, I. Nowik, S. Ofer and J. Yariv, Phys. Rev. Lett., 1981, 46, 1244-1248.

5 E. W. Knapp, S. F. Fischer and F. Parak, J. Phys. Chem., 1982, 86, 5042-5047

6 W. Doster, S. Cusack and W. Petry, Nature, 1989, 337, 754-756.

7 B. F. Rasmussen, A. M. Stock, D. Ringe and G. A. Petsko, Nature, 1992, 357, 423-424.

8 R. F. Tilton, Jr., J. C. Dewan and G. A. Petsko, Biochemistry, 1992, 31, 2469-2481.

9 M. Ferrand, A. J. Dianoux, W. Petry and G. Zaccai, Proc. Natl. Acad. Sci. USA, 1993, 90, 9668-9672.

10 I. E. Iben, D. Braunstein, W. Doster, H. Frauenfelder, M. K. Hong, J. B. Johnson, S. Luck, P. Ormos, A. Schulte, P. J Steinbach, A. H. Xie and R. D. Young, Phys. Rev. Lett., 1989, 62, 1916-1919.

11 J. L. Green, J. Fan and C. A. Angell, J. Phys. Chem., 1994, 98, $13780-13790$

12 C. A. Angell, Science, 1995, 267, 1924-1935.

13 A. L. Tournier and J. C. Smith, Phys. Rev. Lett., 2003, 91, 208106.

14 H. Frauenfelder, S. G. Sligar and P. G. Wolynes, Science, 1991 254, 1598-1603.

15 B. H. McMahon, J. D. Muller, C. A. Wraight and G. U. Nienhaus, Biophys. J., 1998, 74, 2567-2587.

16 A. Ostermann, R. Waschipky, F. G. Parak and G. U. Nienhaus, Nature, 2000, 404, 205-208.

17 R. M. Daniel, J. C. Smith, M. Ferrand, S. Hery, R. Dunn and J. L. Finney, Biophys. J., 1998, 75, 2504-2507.

18 R. V. Dunn, V. Réat, J. Finney, M. Ferrand, J. C. Smith and R. M. Daniel, Biochem. J., 2000, 346 Pt 2, 355-358.

19 R. M. Daniel, J. L. Finney, V. Réat, R. Dunn, M. Ferrand and J. C. Smith, Biophys. J., 1999, 77, 2184-2190.

20 R. M. Daniel, J. L. Finney and J. C. Smith, Faraday Discuss., 2003, 122, 163-169, discussion 171-190. 
21 T. Becker, J. A. Hayward, R. Daniel, J. Finney and J. C. Smith, Biophys. J., 2004, 87, 1436-1444.

22 F. Franks, Biophys. Chem., 2002, 96, 117-127.

23 P. W. Fenimore, H. Frauenfelder, B. H. McMahon and F. G. Parak, Proc. Natl. Acad. Sci. USA, 2002, 99, 16047-16051.

24 R. M. Daniel, R. V. Dunn, J. L. Finney and J. C. Smith, Annu. Rev. Biophys. Biomol. Struct., 2003, 32, 69-92.

25 J. Smith, S. Cusack, P. Poole and J. Finney, J. Biomol. Struct. Dyn., 1987, 4, 583-588.

26 J. M. Zanotti, M. C. Bellissent-Funel and J. Parello, Biophys. J., 1999, 76, 2390-2411.

27 J. Perez, J. M. Zanotti and D. Durand, Biophys. J., 1999, 77, 454-469.

28 D. Ringe, Curr. Opin. Struct. Biol., 1995, 5, 825-829.

29 G. Colombo, G. Ottolina and G. Carrea, Monatsh. Chem., 2000, 131, 527-547.

30 C. Mattos and D. Ringe, Curr. Opin. Struct. Biol., 2001, 11, 761-764.

31 A. Paciaroni, S. Cinelli and G. Onori, Biophys. J., 2002, 83, $1157-1164$

32 A. L. Tournier and J. C. Smith, Biophys. J., 2003, 85, 1871-1875.

33 A. M. Tsai, D. A. Neumann and L. N. Bell, Biophys. J., 2000, 79, 2728-2732.

34 V. Réat, R. Dunn, M. Ferrand, J. L. Finney, R. M. Daniel and J. C. Smith, Proc. Natl. Acad. Sci. USA, 2000, 97, 9961-9966.

35 L. Cordone, M. Ferrand, E. Vitrano and G. Zaccai, Biophys. J., 1999, 76, 1043-1047.

36 M. S. Lehmann, S. A. Mason and G. J. McIntyre, Biochemistry, $1985,24,5862-5869$.
37 M. S. Lehmann and R. F. Stansfield, Biochemistry, 1989, 28, 7028-7033.

38 J. P. Bouquière, J. Finney, M. S. Lehmann and S. Mogens, J. Chem. Soc., Faraday Trans., 1993, 89, 2701-2705.

39 V. Réat, J. L. Finney, A. Steer, M. A. Roberts, J. Smith, R. Dunn, M. Peterson and R. Daniel, J. Biochem. Biophys. Methods, 2000, 42, 97-103.

40 M. Bée, Quasielastic Neutron Scattering: Principles and Applications in Solid State Chemistry, Biology and Material Science, Adam Hilger, Bristol, 1988.

41 W. Marshall and S. W. Lovesey, Theory of Thermal Neutron Scattering, Clarendon Press, Oxford, 1971.

42 J. A. Hayward and J. C. Smith, Biophys. J., 2002, 82, 1216-1225.

43 J. A. Hayward, J. L. Finney, R. M. Daniel and J. C. Smith, Biophys. J., 2003, 85, 679-685.

44 R. D. Lide, in CRC Handbook of Chemistry and Physics, ed. R. C. Weast, CRC Press, Boca Raton, FL, 1993.

45 T. Becker and J. C. Smith, Phys. Rev. E. Stat. Nonlin. Soft Matter Phys., 2003, 67, 21904.

46 J. Lin and C. W. Brown, Vib. Spectrosc., 1994, 7, 117-123.

47 S. Dixit, J. Crain, W. C. Poon, J. L. Finney and A. K. Soper, Nature, 2002, 416, 829-832.

48 S. Dixit, A. K. Soper, J. Finney and J. Crain, Europhys. Lett., 2002, 59, 377-383.

49 J. L. Finney, D. T. Bowron, R. M. Daniel, P. A. Timmins and M. A. Roberts, Biophys. Chem., 2003, 105, 391-409.

50 K. Takaizumi and T. Wakabayashi, J. Solution Chem., 1997, 26, 927-939. 